\title{
Symptomatic sinus bradycardia due to electrolyte imbalances in syndrome of inappropriate antidiuretic hormone (SIADH) related covid-19: a case report
}

\author{
Muzakkir Amir ${ }^{1,2^{*}}$ (D), Andi Renata ${ }^{1,2}$ and Levina Tri Ratana $a^{1,2}$
}

\begin{abstract}
Background: Coronavirus Disease-2019 (COVID-19) has been declared a global pandemic since March 11th, 2020. Despite emerging reports and literature covering a broad spectrum of COVID-19 clinical manifestations, facets of COVID-19 have not been fully elucidated. To the authors' concern, sinus bradycardia as a manifestation of COVID19-induced syndrome of inappropriate antidiuretic hormone (SIADH) has never been reported before.

Case presentation: In this paper, we report a case of a 59-year-old male patient with confirmed COVID-19 initially presented with presyncope. Further investigations reveal sinus bradycardia related to COVID-19-induced SIADH. This case highlights the possibility of immuno-neuroendocrino-cardiovascular crosstalk resulting in an atypical manifestation of COVID-19: near syncope due to sinus bradycardia.
\end{abstract}

Conclusions: Another possible cause of sinus bradycardia in COVID-19 is electrolyte imbalance due to COVID-19related SIADH.

Keywords: Symptomatic sinus bradycardia, Electrolyte imbalances, SIADH, COVID-19

\section{Background}

COVID-19 is a terminology explaining a disease caused by Severe Acute Respiratory Syndrome-Coronavirus 2 (SARS-CoV2). COVID-19 has been declared a global pandemic since March 11th, 2020 [1]. By September 11th, 2020, COVID-19 has spread across 140 countries and has caused over 28.3 million confirmed cases and responsible for nearly 1 million deaths since its first occurrence in December 2019 [2]. COVID-19 were initially considered as primary lung disease, causing severe pneumonia and rapidly fatal acute respiratory distress syndrome (ARDS). Further investigations showed that

\footnotetext{
* Correspondence: muzakkir@unhas.ac.id

'Departement of Cardiology and Vascular Medicine, Hasanuddin University, Makassar, Indonesia

${ }^{2}$ Dr. Wahidin Sudirohusodo National General Hospital, Makassar, Indonesia
}

COVID-19 manifests as several different phenotypes, involving some other organs besides the lungs themselves [3].

SIADH is frequently found in patients with pneumonia and other types of pulmonary infections. Distinguished by euvolemic hyponatremia, decreased plasma osmolality, increased urinary osmolality, elevated natriuresis in the absence of any different potential etiology, SIADH in patients with COVID-19 is currently recognized as a "clue in the times of pandemic" [4, 5]. Presence of SIADH should raise suspicion towards SARS-CoV2 infection. Hyponatremia resulting from COVID-19-induced SIADH has been reported to manifest as neurologic symptoms or as an asymptomatic one [6]. However, in our patient, it manifests primarily as symptomatic cardiac arrhythmia.

Electrolytes play a crucial role in the propagation of cardiac action potential [7]. Cardiac arrhythmias, one of

(c) The Author(s). 2021 Open Access This article is licensed under a Creative Commons Attribution 4.0 International License, which permits use, sharing, adaptation, distribution and reproduction in any medium or format, as long as you give appropriate credit to the original author(s) and the source, provide a link to the Creative Commons licence, and indicate if changes were made. The images or other third party material in this article are included in the article's Creative Commons licence, unless indicated otherwise in a credit line to the material. If material is not included in the article's Creative Commons licence and your intended use is not permitted by statutory regulation or exceeds the permitted use, you will need to obtain permission directly from the copyright holder. To view a copy of this licence, visit http://creativecommons.org/licenses/by/4.0/ The Creative Commons Public Domain Dedication waiver (http://creativecommons.org/publicdomain/zero/1.0/) applies to the data made available in this article, unless otherwise stated in a credit line to the data. 
which sinus bradycardia, have been noted as one of many phenotypes of COVID-19 and hypothesized to be caused by myocardial or pacemaker cell injury [8]. However, there was no previous report concerning symptomatic sinus bradycardia linked to hyponatremia in COVID-19 patients. Hyponatremia in COVID-19 patients is called "a possible immuno-neuroendocrine interface with COVID-19" [9]. Therefore, this case highlights the possibility of an immuno-neuroendocrinocardiovascular interface with COVID-19 resulting in an atypical manifestation: near syncope due to sinus bradycardia.

\section{Case presentation}

A 59-year-old male presented to the emergency unit of dr. Wahidin Sudirohusodo General Hospital with complaints of recurrent near-syncope, which occurred a couple of hours ago. He described the episode as lightheadedness followed by a brief blackout without loss of consciousness. He also had complaints of weakness and fatigue. He had no previous history of similar episodes. He denied any respiratory problems, fever, or close contact with COVID-19 confirmed patients. To his knowledge, he has no underlying cardiovascular conditions and was otherwise healthy. During the examination, he was afebrile, with a blood pressure of $144 / 88 \mathrm{mmHg}$, a heart rate of 44 beats per minute, and a respiratory rate of 20 breaths per minute with oxygen saturation of $94 \%$ on room air. Physical examination was nothing out of the ordinary, with no signs of volume overload or dehydration. Electrocardiogram (ECG) on admission (Fig. 1) showed sinus bradycardia with 44 beats per minute.
High sensitivity Troponin I assay showed $3.8 \mathrm{ng} / \mathrm{L}$. A 2-h repeated assay was performed with a result of $4.9 \mathrm{ng} / \mathrm{L}$.

Laboratory findings were significant for serum sodium of $117 \mathrm{mmol} / \mathrm{L}$ (reference range 136-145 mmol/L), serum potassium of $3.4 \mathrm{mmol} / \mathrm{L}$ (reference range 3.5 $5.0 \mathrm{mmol} / \mathrm{L}$ ) and increased neutrophil/lymphocyte ratio 8,36 (78.6/9.4). Blood urea nitrogen was $11.7 \mathrm{mg} / \mathrm{dL}$ (reference range: $7-20 \mathrm{mg} / \mathrm{dL}$ ) and random blood glucose was $122 \mathrm{mg} / \mathrm{dL}$, resulting in calculated plasma osmolality of $245 \mathrm{mOsm} / \mathrm{kg}$ (reference range: $275-299 \mathrm{mOsm} / \mathrm{kg}$ ). Further workup revealed urine osmolality of $142 \mathrm{mOsm} /$ $\mathrm{kg}$ (reference range: $500-850 \mathrm{mOsm} / \mathrm{kg}$ ) and urinary sodium $34 \mathrm{mmol} / \mathrm{L}$ with low plasma osmolality. Thyroidstimulating hormone and Free T4 were normal (1.77 $\mathrm{mIU} / \mathrm{mL}$ and $1.41 \mathrm{ng} / \mathrm{dL}$ consecutively). The patient was planned to be admitted to the Cardiology Care Unit. However, during the routine COVID-19 screening examination, chest $\mathrm{CT}$ scan revealed multiple groundglass opacities typical for COVID-19 pneumonia. Following the chest CT result, a naso- and oropharyngeal swab for SARS-CoV-2 PCR was obtained from the patient, which came back positive with an IL- 6 result of $13.2 \mathrm{pg} / \mathrm{ml}$. Further workup fulfilled the criteria for SIADH, and other potential causes of hyponatremia were excluded. No other potential etiology of SIADH was found, and the patient was assessed to have a COVID-19-associated SIADH.

The patient was treated with a slow infusion of hypertonic saline and oral potassium supplementation. After the serum sodium concentration normalized, his symptoms and heart rate improved (Table 1), and further ECG monitoring showed no bradycardic events. The patient was given azithromycin and oseltamivir from the

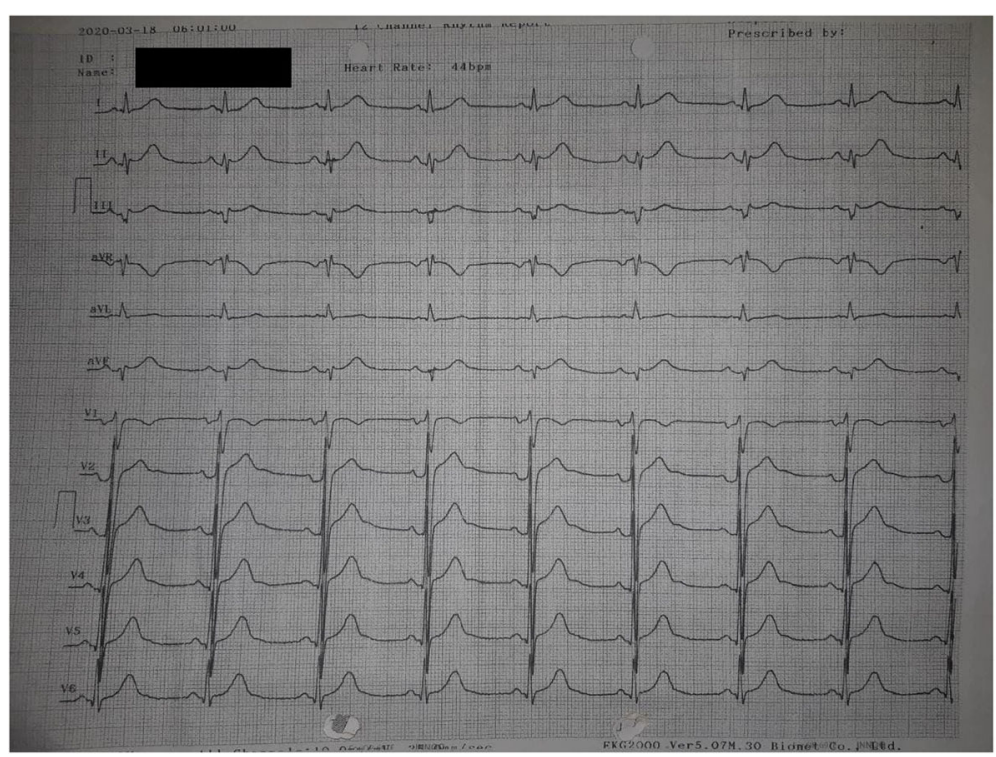

Fig. 1 Electrocardiography showing sinus bradycardia and 44 bpm heart rate 
Table 1 Course of Sodium/Potassium and Electrographic changes

\begin{tabular}{llll}
\hline Hospitalization day & $\left.\mathbf{N a}^{+} \mathbf{( m m o l} / \mathbf{L}\right)$ & $\left.\mathbf{K}^{+} \mathbf{( m m o l} / \mathbf{L}\right)$ & ECG Interpretation \\
\hline 1st & 117 & 3.4 & Sinus Bradycardia, 40 bpm \\
3rd & 118 & 3.7 & Sinus Bradycardia, 50 bpm \\
5th & 132 & 4.1 & Normal Sinus Rhythm, 60 bpm \\
8th & 136 & 4.2 & Normal Sinus Rhythm, 75 bpm \\
11th & 134 & 4.2 & Normal Sinus Rhythm, 72 bpm \\
18th & 135 & 4.0 & Normal Sinus Rhythm, 60 bpm \\
\hline
\end{tabular}

pulmonology department. Despite his asymptomatic state, the nasopharyngeal swab test remains positive until the 30th day of hospitalization. This case is the first case report concerning symptomatic sinus bradycardia related to COVID-19 associated SIADH to the author's concern.

\section{Discussion}

Bradyarrhythmias could be an early manifestation of various cardiac and extracardiac conditions. COVID-19 has been linked to sinus bradycardia by several past reports. Amaratunga et al. reported a group of 4 patients experiencing sinus bradycardia during hospitalization for COVID-19. Extreme hypoxia, inflammatory damage to cardiac pacemaker cells, and an exaggerated reaction to medication were all listed as contributing factors to bradycardia in this study [8]. In contrast to the abovementioned mechanism, bradycardia in our patient occurs under normal oxygen saturation at room air, and the patient was not under any medication. Direct myocardial injury was also excluded from normal 0-h and 2$\mathrm{h}$ high-sensitivity troponin I assay. Significant laboratory result was only electrolyte imbalance. Inflammatory cytokines could also exert a direct effect on pacemaker cells. However, our patient's inflammatory marker did not increase during the bradycardic episode. Furthermore, the patient did not develop any inflammatory or respiratory symptoms until the end of hospitalization. Therefore, symptomatic sinus bradycardia in our patient may be related to other pathways rather than the abovementioned mechanism.

Cardiac arrhythmias related to hyponatremia usually occur in the setting of underlying heart disease, antiarrhythmic drugs, or concomitant with other electrolyte abnormalities. Although the exact mechanism is not clear, severe hyponatremia has been associated with cardiac conduction defects through the genesis action potential. Karabag et al. reported a case of severe hyponatremia with complete heart block that is fully reversible upon normalization of sodium levels, and previously Mouallem et al. also have reported a case series including hyponatremia and various cardiac arrhythmia manifestations [10, 11].

Low extracellular sodium could reduce inward sodium flow in the early phase of the cardiac action potential.
Trautwein et al. showed that low sodium levels in isolated heart muscle perfusate have a negative chronotropic and dromotropic effect [12]. A study by Nikolaidou et al. showed that low sodium levels could affect action potentials in the atrioventricular node [13]. Association between hyponatremia and dysautonomia has also been reported in various other conditions such as Guillain-Barre syndrome and porphyrias $[14,15]$. Our patient has an associated electrolyte abnormality, which is mild hypokalemia. Yet, sinus bradycardia persists upon normalization of plasma potassium levels and improved upon hyponatremia correction.

Interleukin-6 (IL-6) plays an essential role in causing electrolyte imbalance by inducing the non-osmotic release of vasopressin [16]. Released by monocytes and macrophages, IL-6 will result in an inflammatory state which causes multiple organ failure. Berni et al. performed a preliminary study to confirm this condition, and they reported that IL- 6 was inversely correlated with sodium levels. Hyponatremia was associated with more severe conditions $(\mathrm{OR}=14.8,95 \%$ CI $1.5 \pm 144,2, p=$ 0.02) [17]. Although this study is still limited, we agreed that sodium levels must be considered an alternative biomarker in the clinical protocols for COVID-19 patient management and prognosis.

SIADH is characterized by euvolemic hyponatremia, low plasma osmolality, high urinary osmolality, elevated natriuresis, and lack of evidence of other hyponatremic diseases [4]. SIADH was frequently found in patients with pneumonia. A case series by Yousaf et al. highlights SIAD $\mathrm{H}$ as a clue in the time of the pandemic [5]. Habib et al. and Yousaf et al. reported COVID-19 patients who develop SIADH without significant respiratory problems [5, 6]. COVID-19-induced stress stimulates the hypothalamo-hypophyseal axis, or hypothalamic neuron directly, and stimulates ADH release. In animal models, decreased osmolality cause osmoreceptor to fire and increase the ADH. Inflammatory cytokines could directly stimulate the non-osmotic release of ADH [5]. Another pathway in which an inappropriate amount of $\mathrm{ADH}$ could be secreted is via the hypoxic pulmonary vasoconstriction pathway [5], which might be unsuitable in our patient because the patient has no respiratory symptoms and have normal oxygen saturation. SIADH could result in dysautonomia [14]. 


\section{Conclusions}

In this case, we present an atypical manifestation of COVID-19 in an otherwise healthy patient: nearsyncope. It is important to note that bradycardia (and its related symptoms) related to electrolyte imbalance could be the initial and the only manifestation of COVID-19. Therefore, these findings should warrant the clinician to address this unusual presentation carefully to improve patient outcomes and prevent in-hospital COVID-19 transmission.

\section{Abbreviations}

COVID-19: Corona Virus Disease 19; SARS-CoV-2: Severe Acute Respiratory Syndrome-Coronavirus 2; RDS: Acute Respiratory Distress Syndrome; SIAD $\mathrm{H}$ : Syndrome of Inappropriate Antidiuretic Hormone; CT scan: Computed Tomography Scan; IL-6: Interleukin-6; ECG: Electrocardiogram; 0-h: 0-h; 2-h: 2-h

\section{Acknowledgements}

None.

\section{Authors' contributions}

MA, AR, and LV had substantial contributions to the study design and development of the data collection checklist. AR drafted the manuscript. MA and LV wrote and corrected the manuscript. All authors have approved the submitted version (and any substantially modified version that involves the author's contribution to the study) and have agreed both be personally accountable for the author's contributions and to ensure that questions related to the accuracy or integrity of any part of the work, even ones in which the author was not personally involved, are appropriately investigated, resolved, and the resolution documented in the literature.

\section{Funding}

The authors have no sources of funding for the research reported to declare.

\section{Availability of data and materials}

The data that support the findings of this case report was taken from the $d r$. Wahidin Sudirohusodo Hospital's medical record and are available from the corresponding author upon reasonable request.

\section{Declarations}

\section{Ethics approval and consent to participate}

Ethical approval was not required for this case report, and the patient gave his written consent to participate in this case report.

\section{Consent for publication}

Written consent was obtained from the patient for publication of this case report.

\section{Competing interests}

All of the authors declare that they have no competing interests.

Received: 9 March 2021 Accepted: 5 May 2021

Published online: 21 May 2021

\section{References}

1. WHO. Report of the WHO-China joint mission on coronavirus disease 2019 (COVID-19). http://who.int/docs/default-source/coronaviruse/who-chinajoint-mission-on-covid-19-final-report.pdf; 2020.

2. Worldometer. COVID-19 coronavirus. www.worldometers.info/coronavirus/; 2020.

3. Behzad S, Aghaghazvini L, Radmard AR, Gholamrezanezhad A. Extrapulmonary manifestation of COVID-19: radiologic and clinical overview. Clin Imaging. 2020;66:35-41. https://doi.org/10.1016/j.clinimag.2020.05.013.

4. Decaux G, Musch W. Clinical laboratory evaluation of the syndrome inappropriate secretion of antidiuretic hormone. Clin J Am Nephrol. 2008; 3(4):1175-84. https://doi.org/10.2215/CJN.04431007.
5. Yousaf Z, Al-Shokri D, Al-Soub H, Mohamed FH. COVID-19-associated SIADH: a clue in the times of pandemic. Am J Physiol Endocrinol Metab. 2020; 318(6):E882-5. https://doi.org/10.1152/ajpendo.00178.2020.

6. Habib MB, Sardar S, Sajid J. Acute symptomatic hyponatremia in setting of SIADH as an isolated presentation of COVID-19. IDCases. 2020;21:e00859. https://doi.org/10.1016/j.idcr.2020.e00859.

7. Grant AO. Basic science for the clinical Electrophysiologist: cardiac ion channels. Circ Arrhythm Electrophysiol. 2009;2(2):185-94. https://doi.org/1 0.1161/CIRCEP.108.789081.

8. Amaratunga EA, Corwin DS, Moran L, Snyder R. Bradycardia in patients with COVID-19: a calm before the storm? Cureus. Cureus, Inc. 2020. https://doi. org/10.7759/cureus.8599.

9. Tantisattamo E, Reddy UG, Duong DK, Ferrey AJ, Ichii H, Dafoe DC, et al. Hyponatremia: a possible immuno-neuroendocrine interface with COVID-19 in a kidney transplant recipient. Transpl Infect Dis. 2020;8:e13355.

10. Karabag T, Kalayci B, Sayin MR, Erten T. Atrioventricular conduction defect associated with severe hyponatremia. Med Pharmacy Rep Clujul Medical. 2018;91(3):342-5. https://doi.org/10.15386/cjmed-846.

11. Mouallem M, Friedman E, Shemesh Y, Mayan H, Pauzner R, Farfel Z. Cardiac conduction defect associated with hyponatremia. Clin Cardiol. 1991;14(2): 165-8. https://doi.org/10.1002/clc.4960140214.

12. Trautwein W. Generation and conduction of impulses in the heart as affected by drugs. Pharmacol Rev. 1963;15:277-332.

13. Nikolaidou T, Cai XJ, Stephenson RS, Yanni J, Lowe T, Atkinson AJ, et al. Congestive heart failure leads to prolongation of the PR interval and atrioventricular junction enlargement and ion channel remodeling in the rabbit. PLoS One. 2015;10(10):e0141452. https://doi.org/10.1371/journal. pone.0141452.

14. Ramanathan S, McMeniman J, Cabela R, Holmes-Walker DJ, Fung VS. SIADH and dysautonomia as the initial presentation of Guillain-Barré syndrome. J Neurol Neurosurg Psychiatry. 2012;83(3):344-5. https://doi.org/10.1136/ jnnp.2010.233767.

15. Nabin A, Thapa LJ, Paudel R, Rana PVS. Acute intermittent porphyria with SIADH and fluctuating dysautonomia. Kathmandu Univ Med J. 2012;38(2): 96-9.

16. Hodax JK, Bialo SR, Yalcindag A. SIADH in systemic JIA resolving after treatment with an IL-6 inhibitor. Am Acad Pediatr. 2018;141:e20164174.

17. Berni A, Malandrino D, Parenti G, Maggi M, Poggesi L, Peri A. Hyponatremia, IL-6, and SARS-CoV-2 (COVID-19) infection: may all fit together? J Endocrinol Investig. 2020;43(8):1137-9. https://doi.org/10.1007/s40618-020-01301-w.

\section{Publisher's Note}

Springer Nature remains neutral with regard to jurisdictional claims in published maps and institutional affiliations.

\section{Ready to submit your research? Choose BMC and benefit from:}

- fast, convenient online submission

- thorough peer review by experienced researchers in your field

- rapid publication on acceptance

- support for research data, including large and complex data types

- gold Open Access which fosters wider collaboration and increased citations

- maximum visibility for your research: over $100 \mathrm{M}$ website views per year

At BMC, research is always in progress.

Learn more biomedcentral.com/submission 